International Journal of Current Microbiology and Applied Sciences

ISSN: 2319-7706 Volume 6 Number 7 (2017) pp. 2222-2229

Journal homepage: http://www.ijcmas.com

Original Research Article

https://doi.org/10.20546/ijcmas.2017.607.322

\title{
Evaluation of Type of Growth Media on Biologi al Attributes and Virulence of Verticillium lecanii (Zimmermann) Viegas against Mealy Bug
}

\author{
J. Sumalatha*, S. J. Rahman, Tabassum Fatima and K. Nagaswathi \\ Department of Entomology, College of Agriculture, Acharya N. G. Ranga Agricultural \\ University and AICRP on biological control Rajendranagar, \\ Hyderabad-500030, Telangana, India \\ *Corresponding author
}

\section{A B S T R A C T}

Keywords

Paracoccus marginatus,

Evaluation,

Growth and

Attributes.

Article Info

Accepted:

23 June 2017

Available Online:

10 July 2017
In the present investigation on total of 4 different media PDA, SDAY, CMA, MEA were evaluated for their biological attributes and levels of virulence against the target pest, Paracoccus marginatus. Among test media SDAY showed maximum radial growth $(67.39 \mathrm{~mm})$, highest conidial concentration $\left(1.75 \times 10^{9}\right)$, highest percentage of conidial viability (98.68 per cent) and highest virulence against mealy bug (94.00 per cent). PDA found to be the next promising isolate with radial growth of $60.33 \mathrm{~mm}$, conidial concentration of $1.57 \times 10^{9}$, conidial viability of 94.77 per cent and virulence of 90.00 per cent. Least radial growth (44.53 mm), conidial concentration $\left(1.07 \times 10^{9}\right)$, conidial viability (83.28 per cent) and virulence (76.00 per cent) were noticed in SDAY media. The findings of the present investigation also gave information pertaining to the strain development among different media in terms of the above mentioned biological attributes. On the basis of the data obtained and also in the view of above inferences SDAY media recorded good results.

\section{Introduction}

Pathogens of insects and other invertebrates have been identified in more than 100 fungal genera with $>700$ species recognized that attack insect hosts (Roberts and Humber, 1981; Hajek and St. Ledger, 1994). The fungi, Metarhizium anisopliae (Metch.) Sorokin, Beauveria bassiana (Bals.) Vuillemin and Verticillium lecanii (Zimm.) Zare and Gams (2001) have gained great scope as biological control agents in insect pest management. Among EPFs Verticillium lecanii (Zimmermann) Viegas is one of the highly promising fungal bioagent causing infections mostly to members of Homoptera including whiteflies (Horn, 1915; Ekborn, 1979; Kanagaratnam et al., 1982) coccids and aphids (Cortez-Madrigal et al., 2003; Liu et $a l ., 2011)$ considering the ecofriendly benefits of biological control. Verticillium lecanii was also reported to act as hyper parasite of phytopathogenic fungi, mostly rusts and powdery mildews (Ramarethinam et al., 2005).

A deuteromycetes, Verticillum lecanii (Zimmermann) Viegas (Moniliales: 
Moniliaceae) formerly known as Cephalosporium lecanii was first described in 1891 and is a cosmopolitan fungus found on inscets. The fungi $V$. lecanii is known as "White-halo fungus" because of white mycelial growth on the edges of infected scale insects. It was first reported in 1939 by Viegas, who referred to the characteristic white halo formed by the fungus on the scale insect Coccus viridis (Green) as the farmer friend'. The effectiveness of $V$. lecanii was studied and demonstrated first in India by Easwaramoorthy and Jayaraj (1978).

Mealybugs throughout the world cause a variety of economic problems, called 'hard to kill pests of fruit trees'. Perhaps the most important factor is the habitat of the mealybugs. Mealybugs live in protected areas such as cracks and crevices of bark, at bases of leaf petioles, on the underside of leaves and inside the fruit bunch.

Eggs of the mealybugs, protected by waxy filamentous secretions of ovisac are almost impossible to reach with insecticides. Late instar nymphs and adult female mealybugs are not affected by foliar application of insecticides since they are covered with waxy coating (Joshi et al., 2003).

Among the mealybugs, the papaya mealybug, Paracoccus marginatus Williams and Granara de Willink (Hemiptera: Pseudococcidae) is a highly polyphagous insect pest that can damage large number of tropical and subtropical fruits, vegetables and ornamental plants.

Galanihe et al., (2010) recorded more than 40 plant species in Sri Lanka compared to 55 plants species recorded in Florida. $P$. marginatus attacks over 60 species of plants including field crops, fruit trees, ornamentals, weed and scrub vegetation in India.
By keeping this in the back ground, certain investigations pertaining to biological attributes and virulency of $V$. lecanii were carried out with the following set of objectives.

To study the effect of type of growth media on biological attributes of and virulence of Verticillium lecanii (Zimmermann) Viegas against mealy bug.

\section{Materials and Methods}

\section{Studies on biological properties of different isolates of $V$. lecanii}

\section{Preparation of culture media}

A medium is an environment which supplies all nutrients for the growth of an organism. The media study was used to know the best growth of the V.lecanii culture.

There were different media for the growth of fungi. From that the following media was used for the study. PDA (potato dextrose agar), SDAY (sabourauds dextrose agar yeast), CMA (carrot meal agar), MEA (malt extract agar), media are used to culture the fungi.

The cultures were established on the grown media and the fungus was selectively grown on the SDAY media. The composition of SDAY media is given below.

$\begin{array}{ll}\text { Dextrose } & -40 \mathrm{~g} \\ \text { Peptone } & -10 \mathrm{~g} \\ \text { Agar agar } & -15 \mathrm{~g} \\ \text { Yeast extract } & -5 \mathrm{~g} \\ \text { Distilled water }-1000 \mathrm{ml}\end{array}$

Components of PDA medium

Potato $\quad-200 \mathrm{~g}$

Dextrose $\quad-20 \mathrm{~g}$ 
Agar $\quad-20 \mathrm{~g}$
Distilled water- $1000 \mathrm{ml}$

Components of CMA medium

$\begin{array}{ll}\text { Carrots } & -200 \mathrm{~g} \\ \text { Agar } & -5 \mathrm{~g}\end{array}$

Distilled water- $1000 \mathrm{ml}$

Components of MEA medium

Maltose $\quad-50 \mathrm{~g}$

Agar $\quad-20 \mathrm{~g}$

Distilled water- $1000 \mathrm{ml}$

The study was taken up to assess the impact of different types of growth media on radial growth, conidial concentration and conidial viability of $V$. lecanii.

Following types of growth media were taken as treatments to ascertain the best media which can support $V$. lecanii, growth with better biological attributes.

Required components of different test media were individually weighed and dissolved in $100 \mathrm{ml}$ of distilled water by thoroughly mixing using vertex mixer.

After cotton plugging, wrapped with the paper, this media was kept for autoclaving at 121 degrees with $15 \mathrm{lbs}$ pressure for 15 to 20 minutes. After sterilization, the media was allowed to cool to a tolerable temperature for handling. The media was poured into Petri plates and allowed for solidification.

After solidification the plates were inoculated with the pure culture of $V$. lecanii. The plates were kept for incubation at $25 \pm 5^{0} \mathrm{C}$ temperatures for 3 to 5 days.

\section{Treatments}

T1: $\quad$ SDAY medium

T2: $\quad$ PDA medium
T3: CMA medium

T4: MEA medium

\section{Radial growth}

SDAY medium as described earlier was prepared and sterilized in an autoclave. The medium was allowed to cool down after which it was poured in to sterile petriplates of $9.5 \times 1.5 \mathrm{~cm}$. About $100 \mathrm{ml}$ medium was poured evenly in five petriplates and allowed to solidify. Circular discs of $8 \mathrm{~mm}$ diameter were cut from the vigorously grown culture of isolate using a sterile cork borer and were placed in the middle of each Petriplate.

All these steps were carried out under aseptic conditions inside an inoculation chamber sterilized with UV radiation. The Petriplates were incubated at $25 \pm 5^{\circ} \mathrm{C}$. The radial growth of the fungus was measured using a measuring scale at 7, 14 and 21 days after inoculation.

\section{Conidia per unit area}

Suspension of the fungal isolate was made and the conidial concentration of the isolate from different media and $\mathrm{pH}$ was done by using Digital Colony Counter with standard scale for counting number of Colony Forming Units (CFUs).

The circular discs of $8 \mathrm{~mm}$ diameter were cut randomly from the two weeks old uniformly grown culture plates. Each disc was placed in a test tube containing $10 \mathrm{ml}$ of distilled water with $0.02 \%$ Tween- 80 solution. The spores present in the disc were allowed to disperse uniformly in the water by rotating the test tube on a vertex for one minute. Proper care was taken to avoid spillage of the suspension while rotation. The suspension was serially diluted and the spores were counted with the help of an improved Neubaur Haemocytometer under a compound microscope at $40 \mathrm{X}$ magnification and number 
of spores present per ml was calculated using the below mentioned formula (Aneja, 1996). No. of spores per $\mathrm{ml}=$ Total number of spores in 5 randomly selected squares of Haemocytometer x $5 \times 10^{4}$

The readings thus obtained were computed to $10 \mathrm{ml}$ to determine the number of conidia per unit area of $8 \mathrm{~mm}$ diameter disc.

\section{Conidial viability}

The conidial viability was measured in terms of the viable conidia available in the suspension from different $\mathrm{pH}$.

The conidia were harvested from the uniformly grown culture plates with the help of a fine brush into sterile distilled water and filtered through double layered muslin cloth.

Approximately $500 \mu \mathrm{l}$ of uniformly suspended spore solution was placed in the cavities of a cavity slide containing $1000 \mu \mathrm{l}$ of SDAY medium. The slides were placed in a Petriplate containing a moistened filter paper at its bottom and were incubated at a temperature of $25 \pm 5^{\circ} \mathrm{C}$ and relative humidity of 95 per cent. The slides were observed after every hour under microscope till 50 per cent of the conidia visible in any of the focused region got germinated which was recorded as TG-50, the time taken for germination of 50 per cent of spores.

The germination of conidia was recorded after 24 hours of incubation and the per cent spore germination was calculated using the formula.

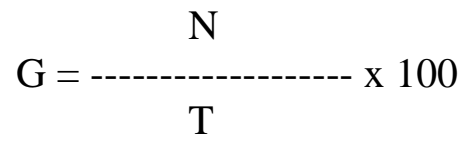

Where,

$\mathrm{G}=$ Per cent spore germination .

$\mathrm{N}=$ Total number of spores germinated.
$\mathrm{T}=$ Total number of spores observed.

Pathogenicity of $V$. lecanii isolate against Paracoccus marginatus

\section{Maintenance of test insect culture}

The pure culture of mealybug, $P$. marginatus was collected from in and around field of Agricultural Research Institute, Rajendranagar and was maintained on sprouted potatoes separately in the laboratory as per standard protocols (Mani and Krishnamoorthy, 1990). The mealybugs were reared on potato sprouts in the laboratory at $26^{\circ} \mathrm{C}$ to $28^{\circ} \mathrm{C}$ temperature and 65 to 70 per cent relative humidity, to maintain the mealybug population being available for further studies.

\section{Rearing of test insect on potato sprouts}

The technique of using sprouted potato as an insectary host for mealybug culture was elaborated by Fisher (1963). Fresh potatoes were procured from the market, washed with clean water and were surface sterilized with bleaching powder or 5 per cent sodium hypochlorite solution. The potatoes after air drying were placed in trays filled with moist sand only ensuring the sand around the potatoes. These trays were kept in rearing room and watered gently. Temperature in the rearing room was maintained between $21^{\circ} \mathrm{C}$ to $25^{\circ} \mathrm{C}$ (Mani and Krishnamoorthy, 1990). Ovisacs of the mealybugs obtained from Parthenium weeds were placed over the sprouts. Mass culture of mealybug was obtained within 20 to 25 days.

\section{Preparation of conidial suspension}

The conidia for the bioassay tests were harvested from the two week old cultures by washing the surface of the plates with 75-100 $\mathrm{ml}$ of sterile distilled water containing 0.02 per cent Tween-20 (Roombach et al., 1986). 
Conidial suspension of $10^{6}$ conidia per $\mathrm{ml}$ was standardized for each isolate after assessing the number of conidia in the suspension with an improved Neubauer Haemocytometer as described earlier.

\section{Inoculation of $\boldsymbol{P}$. marginatus with $\boldsymbol{V}$. lecanii}

Ten Adults of $P$. marginatus were taken in a sterile petriplate lined with filter paper and were directly sprayed with $2 \mathrm{ml}$ conidial suspension using a hand automizer. The test concentrations $10^{6}$ conidia per $\mathrm{ml}$ were replicated 5 times with 10 adults as unit size for each replicate. The experiment was conducted under laboratory conditions with room temperature of $25 \pm 5^{\circ} \mathrm{C}$ and 95 per cent relative humidity. The experiment was laid out under CRD for analysis purpose. Ten adults of treated mealy bugs were released on sprouted potatoes individually in each treatment by a soft camel hair brush. Then mortality of the adults was observed at seven days after treatment and per cent mortality was computed. The experimental data was corrected by using Abbott's formula (Abbott, 1925).

\section{Statistical analysis}

Completely Randomized Design (CRD) with 5 replications was followed for analyzing the data in different experiments. The data was subjected to angular or square root transformation as per the requirement to improve homogeneity of error variances (Gomez and Gomez, 1984).

\section{Results and Discussion}

Evaluation of isolate of $\boldsymbol{V}$. lecanii for their biological attributes (Table 1)

\section{Radial growth}

The average radial growth of $V$. lecanii after 21 days interval showed significant differences among the test media. Maximum radial growth of $67.39 \mathrm{~mm}$ was observed in SDAY media followed by PDA $(60.33 \mathrm{~mm})$, which differed significantly from other two isolates respectively. SDAY differed significantly from all other media there by highlighting its supremacy over the entire test media in terms of radial growth.

CMA was the media with $44.53 \mathrm{~mm}$ radial growth and with least radial growth recorded so far in different media. MEA media recorded $57.73 \mathrm{~mm}$ radial growth which is superior to CMA media but was inferior to SDAY media and PDA media. All treatments were significantly different from each other (Fig. 1).

\section{Conidial concentration}

The variations in conidial concentrations in different test media of $V$. lecanii showed almost similar trends of results obtained as in case of radial growth. SDAY maintained its supremacy by recording highest conidial concentration of $1.75 \times 10^{9}$ conidia per ml which is statistically different from other test isolates. Similarly, PDA, MEA and CMA recorded conidial concentrations of $1.57 \mathrm{x}$ $10^{9}, 1.4 \times 10^{9}$ and $1.07 \times 10^{9}$ conidia per ml, respectively. Despite being inferior to SDAY they were found to be superior to all other test isolates by recording higher conidial concentrations than all other test media. The least conidial concentration was observed in case of CMA media. All the treatments were significantly different from each other.

\section{Conidial viability}

Over all observations of the data obtained from different test media in terms of per cent conidial viability has reconfirmed the promising nature of $V$. lecanii isolate tested in SDAY media by registering highest percentage of conidial viability i.e., 98.68 per cent. With regard to other test media, PDA 
recorded next promising highest percentage of conidial viability i.e., 94.77 per cent, which is superior to other two media but inferior to SDAY media. The media CMA has recorded least per cent of conidial viability i.e., 83.28 per cent. MEA media recorded 92.00 per cent conidial viability which is superior to CMA media but inferior to SDAY and PDA media. All treatments were showed significantly different from each other.

Table.1 Variations in biological attributes of $V$. lecanii in different media and efficacy of $V$. lecanii against mealybug Paracoccus marginatus

\begin{tabular}{|c|c|c|c|c|}
\hline $\begin{array}{c}\text { Treatments } \\
(\text { Media) }\end{array}$ & $\begin{array}{c}\text { Radial } \\
\text { growth } \\
(\mathbf{m m})\end{array}$ & $\begin{array}{c}\text { Conidial } \\
\text { concentration } \\
(\mathbf{\times 1 0}\end{array}$ & $\begin{array}{c}\text { Conidial viability } \\
\text { (per cent) }\end{array}$ & $\begin{array}{c}\text { Per cent } \\
\text { mortality }\end{array}$ \\
\hline PDA & $\begin{array}{c}60.33 \\
(50.94)\end{array}$ & $1.57(7.19)$ & $94.77(76.79)$ & $90.00(73.60)$ \\
\hline SDAY & $\begin{array}{c}67.39 \\
(55.15)\end{array}$ & $1.75(7.59)$ & $98.68(83.38)$ & $94.00(78.92)$ \\
\hline CMA & $\begin{array}{c}44.53 \\
(41.84)\end{array}$ & $1.07(5.93)$ & $83.28(65.84)$ & $76.00(60.75)$ \\
\hline MEA & $\begin{array}{c}57.73 \\
(49.42)\end{array}$ & $1.40(6.79)$ & $92.00(73.72)$ & $88.00(69.91)$ \\
\hline SE(m) \pm & 0.248 & 0.073 & 0.722 & 4.745 \\
\hline CD $(0.05 \%)$ & 0.749 & 0.222 & 2.154 & 10.145 \\
\hline
\end{tabular}

Values are given in parentheses are angular transformed values.

Fig.1 Radial growth of Verticillium lecanii on different media

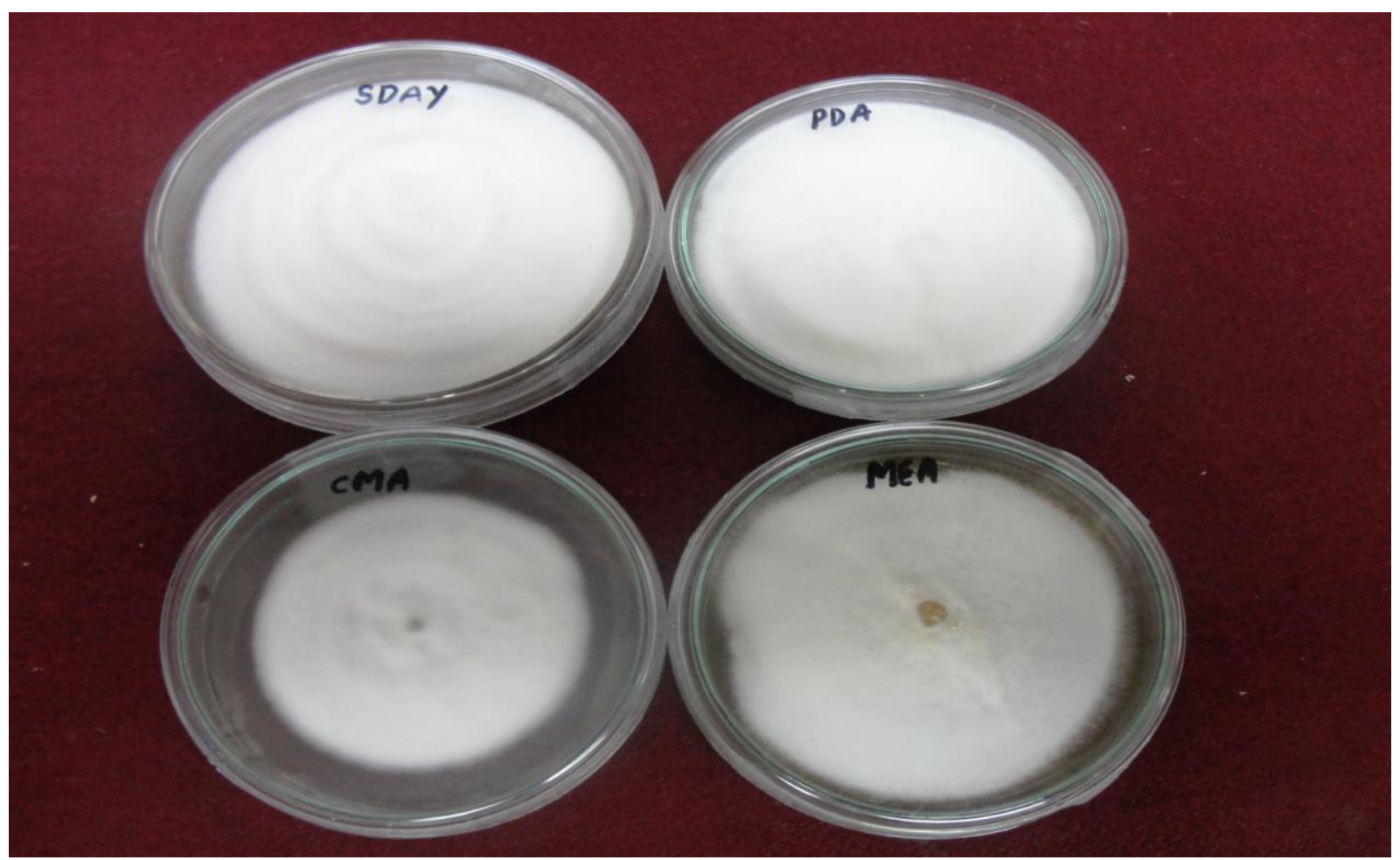


Perusal of the virulence data showed that, SDAY media was found to be more promising with highest per cent virulence of 94 which is statistically superior than 90 per cent obtained from PDA media and 88 per cent obtained from MEA media but statistically on par with each other but significantly different from CMA media. The lowest percent virulence of 76 was observed in CMA media which is statistically inferior to all other media.

\section{Virulence of $V$. lecanii against mealy bug}

Perusal of the virulence data showed that, SDAY media was found to be more promising with highest per cent virulence of 94 which is statistically superior than 90 per cent obtained from PDA media and 88 per cent obtained from MEA media but statistically on par with each other but significantly different from CMA media.

The lowest percent virulence of 76 was observed in CMA media which is statistically inferior to all other media.

The concentration of conidia affected mortality of the aphids differently in all investigated fungal isolates. Mortality of the aphids increased with increase in spore concentration and exposure time. The fungal isolate $V$. lecanii (V17), with $\mathrm{LC}_{50}$ of $1.88 \times$ $10^{6}$ conidia $\mathrm{ml}^{-1}$ was considered the most virulent isolate among investigated fungal isolates as observed by Asi et al., (2009). Gulsar Banu (2013) reported similar results that amongst various grains tested, spores multiplied on rice and sorghum recorded maximum mortality of $96 \%$ at 9 days after inoculation against adults of Paracoccus marginatus.

The above results established that the SDAY medium is the best in terms of the above mentioned biological attributes. On the basis of the data obtained and also in the view of above inferences SDAY media containing $\mathrm{pH}$ 6 recorded good results.

\section{References}

Abbott, W.S. 1925. Method of computing effectiveness of an insecticide. Journal of Economic Entomology. 18: 265-267.

Aneja, K.R. 1996. Experiments in microbiology, plant pathology and tissue culture. Wishwaprakasham, New Delhi (A division of Wiley Eastern Limited). 31.

Asi, M.R., Bashir, M.h., Afzal, M and Imran, S. 2009. Effect of conidial concentration of entomopathogenic fungi on mortality of cabbage aphid, Brevicoryne brassicae L. Pakistan Journal of Life and Social Sciences. (2): 175-180.

Easwaramoorthy, S and Jayaraj, S. 1978. Effectiveness of the white halo fungus Cephalosporium lecanii, against field populations of coffee green bug, Coccus viridis Green. Journal of Invertebrate Pathology. 32: 88-96.

Fisher, T.W. 1963. Mass culture of Cryptolaemus and Leptomastrix natural enemies of citrus mealybug. Bull. Calif. Agric. Exp. Sta., No. 797. 39.

Galanihe, L.D., Jayasundera, M.U.P., Vithana, A., Asselaarachchi, $\mathrm{N}$ and Watson G.W. 2010. Occurrence, distribution and control of papaya mealybug, Paracoccus marginatus (Hemiptera: Pseudococcidae), an invasive alien pest in Sri Lanka. Tropical Agricultural Research and Extension. 13(3): 81-86.

Gomez, K. A and Gomez, A. A. 1984. Statistical procedure for Agricultural Research, John Wiley and Sons, New york. $2^{\text {nd }}$ ed. 304-311.

Gulsar Banu, J. 2013. Effect of Solid subtrates on growth and sporulation of 
Lecanillium lecanii and pathogenic activity to mealy bug. Annals of Plant protection Science. 21(1): 176-223.

Joshi, S., Prashanth Mohanraj, Rabindra, R. J and Rao, N. S. 2003. Production and use of coccinellid predators. Project Directorate of Biological Control, Bangalore. Technical Bulletin. 32: 26.

Mani, M and Krishnamoorthy, A. 1990. Evaluation of the exotic predator, Cryptolaemus montrouzieri Muls. (Coccinellidae: Coleoptera) in the suppression of green shield scale Chloropulvinaria psidii (Maskell)
(Coccidae: Homoptera). Entomon. 15: 45-48.

Ramarethinam, S., Marimuthu, S and Murugesan, $\quad$ N.V. 2005. Entomopathogenic fungi, Verticillim lecanii - An overview. Pestology. 31(12): 9-28.

Roombach, M.C., Aguda, R.M., Shephard, B.M and Roberts, D.W. 1986. Infection of rice brown plant hopper, Nilaparvata lugens by field application of entomopathogenic hyphomycetes. Environmental Entomology. 15: 10701073.

\section{How to cite this article:}

Sumalatha, J., S.J. Rahman, Tabassum Fatima and Nagaswathi, K. 2017. Evaluation of Type of Growth Media on Biological Attributes and Virulence of Verticillium lecanii (Zimmermann) Viegas against Mealy Bug. Int.J.Curr.Microbiol.App.Sci. 6(7): 2222-2229. doi: https://doi.org/10.20546/ijcmas.2017.607.322 